\title{
VARIANTS OF HYPERLIPIDEMIA IN CHILDREN WITH INSULIN RESISTANCE
}

\author{
Chaychenko T., Kharkova M., Rybka O. \\ Kharkiv National Medical University, Ukraine \\ https://doi.org/10.35339/ic.7.1.23-25
}

\begin{abstract}
Obesity in adults and children is characterized by epidemiological prevalence with a tendency to increase. The purpose of the study was to analyze the lipid profile in overweight children, depending on the presence of insulin resistance. 247 overweight and obese children aged 2 to 18 were examined, including 160 boys and 87 girls. Obesity was diagnosed if the BMI exceeded 97 percentile, according to gender and age. Assessment of the lipid profile included measurements of total cholesterol, triglycerides, low-density lipoprotein, and high-density lipoprotein. To evaluate the parameters of the lipid profile, we used the National Cholesterol Education Program (NCEP) according to the latest edition (2006). Lipid values depending on the presence or absence of insulin resistance were analyzed. BMI was also evaluated according to Z-BMI. Insulin resistance was detected in $69.9 \%$ of children. Hyperlipidemia was detected in $24.9 \%$ of children and dyslipidemia in $83 \%$ of the children examined. A change was found in all indicators of the lipid profile, depending on the presence of insulin resistance. A significant increase in Z-BMI was revealed depending on the presence of insulin resistance. Conclusions: the majority of overweight children have insulin resistance and dyslipidemia; the type of dyslipidemia in children with obesity directly depends on the presence of insulin resistance.
\end{abstract}

Key words: Hyperlipidemia, insulin resistance, obesity, pediatrics.

\section{Introduction}

The prevalence of obesity in the world has reached an epidemic level [1]. The prevalence of obesity in children is on the special focus [2]. The prevalence of obesity in Ukraine among children aged 0 to 17 years in 2016 was 16.41 cases per 1000 urban children and 11.90 per 1000 rural children [3]. The pediatric obesity epidemic has resulted in population of children with abnormal lipids. Obesity related dyslipidemia includes combination of elevated triglycerides, decreased high density lipoprotein cholesterol, and high normal or slightly elevated low density lipoprotein cholesterol [4].

\footnotetext{
Corresponding Author:

Mariya Kharkova MD, PhD student,

Department of Pediatrics № 1 and Neonatology,

Kharkiv National Medical University, Ukraine.

E-mail: M.kharkova19@gmail.com
}

Obesity is one of the main causes of insulin resistance (IR) development [5], which plays a major role in the relationship between obesity and dyslipidemia [6].

Overweight and obesity, impaired glucose metabolism, dyslipidemia and hypertension are the basis of metabolic syndrome (MetS). The prevalence of MetS in children and adolescents is increasing, in parallel with the pediatric obesity incline. Obese children have an increased risk of MetS in their adulthood and become prone to type 2 diabetes mellitus and cardiovascular diseases [7].

Thus, it is important to assess the relationship between lipids and insulin resistance as a components of the MetS in obese children with the purpose of better understanding potential cardiovascular risk.

\section{Purposes, subjects and methods:}

2.1 The purpose of the work was to analyze the lipid profile in overweight children depending on the presence of insulin resistance. 


\subsection{Subjects and Methods}

247 overweight and obese children (160 boys and 87 girls) aged 2 to 18 were examined in the pediatric endocrinology department. The diagnosis was made according to the national standard [8]. THE Patients' height (in $\mathrm{m}$ ) and weight (in $\mathrm{kg}$ ) were measured according to standard procedures and followed by the calculation of body mass index (BMI). Obesity was diagnosed when BMI exceeded 97 percentile for gender and age. For further analysis BMI standard deviation (Z-BMI) evaluated by WHO charts were used [9].

Blood samples were collected at fasting state (at least 8-hours after the last meal). Assessment of the lipid profile included measurements of total cholesterol (TC), triglycerides (TG), low-density lipoproteines (LDL), and high-density lipoproteins (HDL). To evaluate the lipid parameters, recommendations of the latest edition of the National Cholesterol Education Program (NCEP) (2006) were used [10].

To assess carbohydrate metabolism, fasting blood glucose and insulin levels were measured followed by HOMA-IR calculation. Insulin resistance was determined if HOMA-IR values exceeded the recommendations of the IDEFICS [11]. The parameters were grouped by the presence (IR+) or absence (IR-) of insulin resistance.

Standard statistics was used for the data analysis. P-values were two-sided and values $<0.05$ were considered statistically significant.

Declaration of Ethics. The patients were informed about the study, its purpose and possible results. Written informed consent was obtained from the patients and their parents. The study was approved by the Ethics Committee of Kharkiv National Medical University (Ethics Committee Protocol No.8 from 03.10.2018) and conducted in accordance with the recommendations of the ethical committees on biomedical research, the legislation of Ukraine on health, the Helsinki Declaration 2000 and European Society Directive $86 / 609$ on the role of people in biomedical research.

Conflict of interests. There is no conflict of interests.

\section{Results}

Insulin resistance was detected in $69.9 \%$ of children; $72 \%$ of the examined girls and in $68 \%$ of the examined boys were insulin resistant. Insulin resistant subjects had statistically higher BMI than insulin sensitive ones $(\mathrm{P}<0.05)$.

Hyperlipidemia was detected in $24.9 \%$ and dyslipidemia in $83 \%$ of the surveyed children. Dyslipidemia was found in 96\% IR+ children and in $86 \%$ of IR- children $(\mathrm{P}=0.012)$, which means that insulin resistant overweight were more dyslipidemic.

Average level of TC was moderately elevated in children with insulin resistance, whereas average level of TC was within normal ranges in children without insulin resistance (table).

HDL values are borderline reduced in overweight children regardless of the presence of insulin resistance.

TG in children without insulin resistance are borderline elevated in both IR+ and IR- children with excessive body mass.

The average LDL levels were significantly increased in IR + group $(p<0.05)$.

\section{Discussion}

Insulin resistance seems to play a key role in the metabolic status in obese subjects. Our findings showed significant difference in LDL-C levels with a relevant tendency for the TC and TG.

The study by Marko Kostovski et al. that included 96 obese children ( 45 boys, 51 girls) aged 4-17 years showed that insulin resistant children had higher BMI and more increased TG than noninsulin resistant ones [12]. Atabek ME et al. came to the similar conclusions in their study which included 196 obese children aged 7-18 years [13].

Romualdo M.C. et al. investigated 220 children aged 5-14 years and met the same results concerning BMI and TG, but they established that median total cholesterol, and LDL-C were increased and HDL-C were decreased in the presence of IR [14]. It is s somewhat different from the data that we obtained as we did not established significant difference in TC and HDL-C levels between groups.

Lipid profile in children with varying degrees of excess body weight, depending on the presence or absence of insulin resistance

\begin{tabular}{|l|c|c|c|}
\hline & $\begin{array}{c}\text { IR+ } \\
\mathrm{N}=137\end{array}$ & $\begin{array}{c}\text { IR- } \\
\mathrm{N}=59\end{array}$ & $\mathrm{P}$ \\
\hline$Z-B M I$ & $2.38 \pm 0.61$ & $2.11 \pm 0.41$ & $<0.05$ \\
\hline $\mathrm{TC}, \mathrm{mmol} / \mathrm{l}$ & $4.64 \pm 1.02$ & $4.32 \pm 1.03$ & 0.06 \\
\hline $\mathrm{TG}, \mathrm{mmol} / \mathrm{I}$ & $1.65 \pm 0.77$ & $1.42 \pm 0.56$ & 0.14 \\
\hline $\mathrm{LDL}, \mathrm{mmol} / \mathrm{l}$ & $2.40 \pm 0.97$ & $1.69 \pm 0.81$ & $<0.05$ \\
\hline $\mathrm{HDL}, \mathrm{mmol} / \mathrm{I}$ & $1.22 \pm 0.25$ & $1.20 \pm 0.31$ & 0.67 \\
\hline
\end{tabular}


A direct correlation between BMI and IR was also confirmed in the study conducted by Ling $\mathrm{J}$ et al. in which BMI statistically significantly positively correlated just with fasting insulin and HOMA-IR, whereas lipids were not predictive for IR in obese children [15].

Our findings demonstrate that IR in obese subjects is associated with cardiovascular risk related dyslipidemia (elevated LDL-C). Meantime, differences when compared with the data of other researchers can be explained by the different degree of adiposity, ethnicities and puberty stages of participants. Furthermore, there is no reason to neglect dyslipidemia as an important risk factor of the cardiovascular risk in children of different age.
It is worth mentioning that the study of the interplay between carbohydrate and lipid metabolism in obese children must be continued as it may well become an important early predictor of clinical events in adulthood.

\section{Conclusions}

1. The majority overweight children are insulin resistant.

2. Global data on the increase of Z-BMI in insulin resistant obese children were confirmed.

3. The type of dyslipidemia in obese children depends on the presence of insulin resistance.

4. Increased LDL-C levels in insulin resistant obese children is an alarming predictor of cardiovascular problems in the future.

\section{References}

1. WHO fact sheet № 311, jan.2015. Available from: URL: http://www.who.int/mediacentre/factsheets/ fs311/en/

2. Styne D.M., Arslanian S.A., Connor E.L., Farooqi I.S., Murad M.H., Silverstein J.H., Yanovski J.A. (2017). Pediatric Obesity-Assessment, Treatment, and Prevention: An Endocrine Society Clinical Practice Guideline. J Clin Endocrinol Metab, 102(3), 709-757, doi: 10.1210/jc.2016-2573.

3. Zelins'ka N., Rudenko N. (2017). Dytjacha endokrynologija v Ukrai'ni: Statystychni pokaznyky za pidsumkamy 2016 roku ta i'h dynamika. [Child endocrinology in Ukraine: statistical indicators for pidums 2016 rock and ix dynamics.] Ukrai'ns'kyj zhurnal dytjachoi' endokrynologii'. 2 (22) pp. 5-17.

4. Cook S., Kavey R. E. W. (2011). Dyslipidemia and Pediatric Obesity. Pediatr Clin North Am, 58(6), 1363-1373. doi:10.1016/j.pcl.2011.09.003.

5. Berenson G. S. (2009). Cardiovascular risk begins in childhood: a time for action. The American Journal of Preventive Medicine, 37 (1), S1-S2.

6. Lewis G. F., Carpentier A., Adeli K., Giacca A. (2002). Disordered fat storage and mobilization in the pathogenesis of insulin resistance and type 2 diabetes. Endocrine Reviews, 23(2), 201-229

7. Al-Hamad D., Raman V. (2017). Metabolic syndrome in children and adolescents. Transl Pediatr, 6(4), 397-407. doi: 10.21037/tp.2017.10.02

8. Nakaz MOZ Ukraïni №254 vid 27.04.2006 "Pro zatverdzhennya protokoliv nadannya medichnoi dopomogi dityam za special'nistyu "Dityacha endokrinologiya"

9. WHO BMI-for-age (5-19 years), 2007. Available from: URL: https://www.who.int/growthref/ who2007_bmi_for_age/en/

10. Jolliffe C. J., Janssen I. (2006). Distribution of Lipoproteins by Age and Gender in Adolescents. Circulation, 114 (10), 1056-1062.

11. Peplies J., Jimenez-Pavon D., Savva S.C., Buck C., Gunther K., Fraterman A., ... Ahrens W. (2014). Percentiles of fasting serum insulin, glucose, HbA1c and HOMA-IR in pre-pubertal normal weight European children from the IDEFICS cohort. International Journal of Obesity, 38 (39-47). doi:10.1038/ijo.2014.134

12. Kostovski M., Simeonovski V., Mironska K., Tasic V., Gucev Z. (2018). Metabolic Profiles in Obese Children and Adolescents with Insulin Resistance. Open Access Maced J Med Sci, 6(3): 511-518. doi: 10.3889/oamjms. 2018.097

13. Atabek ME., Pirgon O., Kurtoglu S. (2007). Assessment of abnormal glucose homeostasis and insulin resistance in Turkish obese children and adolescents. Diabetes Obes Metab, 9(3):304-10.

14. Romualdo MC., Nobrega FJ., Escrivao MA. (2014). Insulin resistance in obese children and adolescents. J Pediatr (Rio J), 90(6):600-7.

15. Ling JC., Mohamed MN., Jalaludin MY., Rampal S., Zaharan NL., Mohamed Z. (2016). Determinants of High Fasting Insulin and Insulin Resistance Among Overweight/Obese Adolescents. Sci Rep, 6():36270. 